\title{
Improvement of Phaseolus vulgaris growth by inoculation with multifunctional native rhizobacteria isolated from rhizospheric soils in Gaza strip- Palestine
}

\author{
N.S. Abu Hujier ${ }^{a}$, Sh. M. Abdelsalam*b, F.A. Sharif ${ }^{\text {c }}$ M. I. Fahd ${ }^{\text {b }}$ \\ ${ }^{a}$ Medical Sciences department - University College of Science and Technology, Gaza Strip, \\ Palestinian territories. E-mail: niddalh@gmail.com. Tel: 00201225038083. \\ botany department, faculty of women for Arts, Science and Education, Ain Shams University, \\ Cairo, Egypt. E-mail: shimaa.abdelsalam@women.asu.edu.eg \\ ${ }^{\mathrm{c}}$ Medical Technology department, faculty of Health Science, Islamic University of Gaza, Gaza \\ Strip, Palestinian territories. E-mail: fsharif@iugaza.edu.ps
}

\begin{abstract}
Overuse of chemical firtilizers is a global problem that had a negative impact on soil comosition and its microbial communities. The present study was conducted to isolate, identify plant growth promoting rhizobacteria (PGPR) associated with (Phaseolus vulgaris) in Gaza strip - Palestine and to determine bacterial inoculations/coinoculations that can enhance plant growth. A total of 35 different morphological isolates were collected and examined for plant growth. Five isolates that were tentatively promising (in plant growth promoting traits i.e. IAA production, $\mathrm{Zn}$ solubilization, ACC deaminase activity and phytase production), were selected and subjected to partial 16S rDNA gene sequencing. The five isolates were: Bacillus proteolyticus MK123398, Bacillus wiedmannii MK123399, Pseudomonas plecoglossicida MK123400, Pseudomonas cedrina MK123401 and Bacillus xiamenensis MK123402. Results indicated that some bacterial combinations significantly increased plant growth, but no significant increase of total nitrogen concentration was observed. Consortia of (B. proteolyticus $+B$. xiamenensis $), \quad(P$. plecoglossicida $+P$. cedrina $),(B$. proteolyticus $+B$. wiedmannii + B. xiamenensis $)$, (B. proteolyticus $+P$. plecoglossicida $+B$. xiamenensis $), B$. wiedmannii $)$, and $(B$. wiedmannii $+P$. plecoglossicida) showed significant increase in plant growth respectively. Those bacterial consortia have the potential for developing biofertilizers for integrated nutrient management strategies and decrease chemical firtilizers abuse stratiges.
\end{abstract}

Keywords: Phaseolus vulgaris; Rhizobacteria; Pseudomonas, Bacilli.

*Corresponding author: Sh. M. Abdelsalam, Botany department, faculty of women for Arts, Science and Education, Ain Shams University, Cairo, Egypt.

ORCID: https://orcid.org/0000-0002-7963-1184

E-mail: shimaa.abdelsalam@women.asu.edu.eg

Tel: 00201006208264 


\section{Introduction}

Beans are the most important grain legumes for direct human consumption in the world. In nutritional terms, and in addition to protein contents, the values for magnesium, iron, (vitamin B1), and folates are remarkably high in beans, even the trace element levels are relatively high in the case of iron, zinc and copper [1]

The use of microorganisms with the aim of improving nutrients availability for plants is an important practice and necessary for agriculture. This symbiosis is a prime example of an intimate relationship between a soil bacterium and its host plant and illustrates the concept behind the term 'plant growth promoting rhizobacteria' (PGPR) [2].

Fertilizer prices are increasing day by day so becoming unaffordable by poor farmers, depleting soil fertility due to widening gap between nutrient removal and supplies, growing concern about environmental hazards and increasing threat to sustainable agriculture. Moreover, the long-term use of biofertilizers is economical, eco-friendly, more efficient, productive and accessible to farmers than chemical fertilizers [3].

PGPR can promote growth by various mechanisms like production of phytohormones, symbiotic nitrogen fixation, solubilization of mineral phosphates and other nutrients, antagonism against phytopathogens by production of siderophores, chitinases, antibiotics, and by lowering endogenous levels of plant hormone "ethylene" in roots [4].

A variety of beneficial rhizosphere microorganisms, including Bacillus, Pseudomonas, Acinetobacter, Azospirillum and Enterobacter species, are commonly found in the rhizosphere of leguminous and non-leguminous crops [5]. Pseudomonas spp. are a major component of the microbial flora which live in close association with various types of agricultural crops. Their association 
with plant materials has been related to their ability to colonize and produce plant growth promoting compounds within the rhizosphere [6,7].

Co-inoculation of many strains of Pseudomonads and Bacillus can upgrade plant growth significantly. Tilak et al.(2006) concluded that growth, nodulation and enzymes activity were significantly increased in plants co-inoculated with Pseudomonas putida, P. fluorescens and Bacillus cereus compared with those inoculated only with Rhizobium [8].

Many studies have described Bacillus strains as effective PGPR agents [9], such as B. subtilis, B. megaterium, B. licheniformis, B. amyloliquefaciens, and B. pumilus $[10,11]$ that exhibited a variety of plant growth promotion effects on many crop species.

Most inoculants often rely on application of a single strain which might partially account for the recorded inconsistencies in the field. In order to enhance the reliability and efficacy of microbial inoculants in agriculture and combining these PGPB by co-inoculation had been applied worldwide for more than a decade. As co-inoculation would mimic the natural situation more closely and allow the combination of various mechanisms without the need for genetic engineering [12].

In the Gaza strip of Palestine, few previous studies have been conducted regarding the isolation of native root PGPR, in addition to the role of PGPR in inorganic bioavailability or growth promotion. The present study was designed to isolate PGPR from the common bean rhizosphere in Gaza strip, define and identify the most promising isolates according to their plant growth promoting traits and evaluate the effect of inoculation/co-inoculation of identified PGPR on common bean growth.

\section{Materials and Methods}




\section{Study area}

Samples were collected from Beit lahia city, northern area of Gaza strip. Sand dunes are predominant in this city particularly in the west of Beit Lahia [13].

\section{Isolation of Phaseolus vulgaris rhizobacteria}

Rhizosphere samples from healthy Phaseolus vulgaris seedlings were obtained from five plants randomly from different fields. Samples were collected in sterile plastic bags and carried to the laboratory in an ice box where they were immediately processed to isolate rhizobacteria. One gram of root adhering soil was suspended in $100 \mathrm{ml}$ of sterile saline solution and kept at $30^{\circ} \mathrm{C}$ for $30 \mathrm{~min}$ with shaking $(200 \mathrm{rpm})$ in an orbital shaker, then diluted up to $10^{-6}$ level. After agitation, an aliquot of $100 \mu \mathrm{l}$ from each dilution was evenly spread-plated over the surface of nutrient agar (NA) and trypticase soy agar (TSA) media $[14,15]$. Plates were incubated at $30^{\circ} \mathrm{C}$ for $12-48 \mathrm{~h}$. Each morphologically different colony was isolated on a new suitable agar plate.

\section{Evaluation of plant growth promoting (PGP) traits}

\subsection{Quantitative determination of indole production}

Purified rhizobacterial isolates were tested for Indole Acetic Acid (IAA) production following the spectrophotometric method of Maleki et al., (2010) [16]

\subsection{Qualitative determination of zinc solubilization activity}

Zinc solubilization activity of the isolates was assayed by the plate method described by [17]. 


\subsection{Qualitative determination of inorganic phosphate solubilization}

Phosphate solubilization ability of the isolates was tested on Pikovskaya's (PVK) agar containing Tricalcium phosphate (TCP) [18].

\subsection{Quantitative determination of 1-aminocyclopropane-1-carboxylate (ACC) deaminase activity}

Three culture conditions were used: M9 minimal medium alone as a negative control; M9 minimal medium plus $\left(\mathrm{NH}_{4}\right)_{2} \mathrm{SO}_{4}\left(2 \mathrm{~g} \mathrm{l}^{-1}\right)$ as a positive control and M9 minimal medium plus $3 \mathrm{mmol}^{-1} \mathrm{ACC}$ as the selective medium. Actively growing bacterial isolates were tested after 24 and $48 \mathrm{~h}$ employing the spectrophotometric method $[4,19,20]$

\subsection{Quantitative determination of phytase production}

This trait was tested according to the procedure described by Saiyad et al., (2015) [5].

\section{Detection of the antagonistic activities against phytopathogenic fungi in- vitro}

The antifungal activity against mycelial growth of Fusarium oxysporum ( $F$. oxysporum) and Macrophomina phaseolina (M. phaseolina) species was determined by dual culture technique according to [21].

\section{Detection of compatibility between selected isolates}

Nutrient agar plates were inoculated separately with $1 \mathrm{ml}$ of the tested isolates, and incubated at $37^{\circ} \mathrm{C}$ for $24 \mathrm{~h}$. Then, slabs of $10 \mathrm{~mm}$ and $7 \mathrm{~mm}$ in diameter were cut and placed on agar plates inoculated with $0.5 \mathrm{ml}$ containing $1 \times 10^{7} \mathrm{cfu}$ of indicator strain culture. After $24 \mathrm{hs}$ of incubation at $37^{\circ} \mathrm{C}$ the plates were checked for inhibition zones [22,23] 


\section{Selection of isolates for subsequent pot experiment}

The selection criteria relied on best performance in plant growth promoting traits, and lack of antagonistic activity against other isolates.

\section{Taxonomical identification}

Colonies from $24 \mathrm{~h}$ old cultures were placed in test tubes containing one $\mathrm{ml}$ of sterile distilled water, subjected to boiling at $100^{\circ} \mathrm{C}$ in a water bath for 10 min, cooled on ice and centrifuged at $15,000 \mathrm{~g}$ for $10 \mathrm{~s}$. The carefully collected supernatant was stored at $-20^{\circ} \mathrm{C}$. Aliquots of $2 \mu \mathrm{l}$ of supernatant (containing template DNA) were used for PCR ([24]. PCR partial amplification of the 16S rRNA gene was performed using the primer sets:

16S-F: 5'-AGAGTTTGATCCTGGCTCAG-3', and 16S-R: 5' ACGGCTACCTTGTTACGACTT-3'

Partial sequences of the PCR products were obtained using the primer: 5'TTACCGCGGCTGCTGGCAC-3' [25]. Sequencing processes were performed in the Islamic University of Gaza.

The search for similarity amongst sequences of the 16S rRNA gene was performed using Basic Local Alignment Search Tool (BLASTn) with the nonredundant database of GenBank, (http://www.ncbi.nlm.nih.gov). Phylogenic trees and evolutionary distances of $16 \mathrm{~S}$ rDNA sequences were calculated using the Fast-Minimum Evolution model.

\section{Plant growth experiment using selected rhizobacteria isolates}

The selected five promising isolates were tested as bio-inoculants at semicontrolled environmental green house of the Ministry of Agriculture in Khan Younis city at the end of September 2017 and the data were recorded weekly till flower phase [26]. 
Seeds of "Garden bean", variety TEMA (Seminis Seed Co. USA) were surface sterilized in $80 \%(\mathrm{v} / \mathrm{v})$ ethanol for $30 \mathrm{~s}$, then in $5 \%(\mathrm{w} / \mathrm{v})$ sodium hypochlorite for 2 min before washing nine times in sterilized distilled water. The seeds were planted in pots (seven liters capacity) filled with non-sterile composted commercial potting soil. A total of 19 treatments with three replicates made up of five isolates in their respective combinations were planted. Seeds in each pot were then inoculated/co-inoculated with $50 \mathrm{ml}$ of a fresh bacterial suspension (in sterile water) adjusted to an abundance of $1.0 \times 10^{8}$ cells ml$^{-1}$ $\left(\mathrm{O} \mathrm{D}_{600}=1\right)$ for Gram positive isolates and $1.0 \times 10^{8}$ cells $\mathrm{ml}^{-1}\left(\mathrm{O}^{\mathrm{D}} \mathrm{D}_{600}=0.5\right)$ for Gram negative isolates [27]. Control plants were inoculated with water. The experiment was designed with three replicates of five seeds per treatment, then the best three seedlings were subjected to subsequent proceedings. Pots were watered twice a week and placed in shade net germination nursery at $13-24^{\circ} \mathrm{C}$.

\section{Estimared plant parameters}

Seedlings growth as effected by selected isolates were monitored by recording root length, shoot height, leaves number per plant, leaf surface area, fresh weight, dry weight and total nitrogen percentage.

Roots were stretched to measure their length from the base of the stem to the tip of the root system [28]. Shoot heights were measured weekly in three-tagged plants in each treatment from the ground level to the tip of main stem with the help of meter scale. Leaves area were determined by millimeter graph paper. The area of the graph paper covered by the outline was cut and estimated [29]. For fresh weight estimation, plants were carefully shaken and washed under running tap water to remove attached soil. Each seedling was immediately weighed by an electronic balance. Plants were dried in an oven at $70{ }^{\circ} \mathrm{C}$ to constant weight and the average dry weight per plant was calculated [26]. 
Nitrogen contents were measured in the obtained extracts by Automatic Distillation Unit (UDK 149), at University College of Science and Technology in Gaza strip. The UDK 149 is designed to perform nitrogen and protein content determination according to the Kjeldahl Method (Velp Scientifica - UDK149 Operating Manual).

\section{Statistical analysis}

All data were subjected to statistical analysis of variance (ANOVA) using IBM SPSS statistics 20 and the differences between the means obtained were separated using Tukey's test.

\section{Results}

A total of 35 morphologically distinct rhizobacteria were isolated from five different Phaseolus vulgaris country estate of Beit Lahia using different isolation media. They were initially coded from BLR1 to BLR35 (from Beit Lahia Rhizosphere).

\section{Characteristics of the isolated PGPR strains}

Twenty-four isolates were selected as promising according to PGP traits, Table (1). Excluded isolates showed negative results in most PGP traits.

\section{Selection and establishment of bacterial consortia for pots experiment}

The selection criteria relied on the best performance in plant growth promoting traits (at least $50 \%$ of growth traits are positive), if results of some isolates were similar, the one with higher scores was chosen as a representative, compatibility between isolates, and selected isolates should collectively fulfill all tested growth promoting parameters. Isolates that achieved the set standards were BLR5, BLR16, BLR21, BLR26, and BLR35 and consortia were designed 
according to all possible combinations between the five isolates, any antagonistic manifestations were excluded from the consortia list.

\section{Identification by partial 16S rDNA gene sequencing}

The amplification products were illustrated in figure (1). The obtained amplicons were sequenced and according to BLASTn, the five selected bacterial strains were assigned to two genera: Pseudomonas and Bacillus on the basis of their partial 16S rDNA gene sequence, Table (2). The sequences were deposited in GenBank and assigned the accession numbers indicated in parentheses: BLR5 (MK123398), BLR16 (MK123399), BLR21 (MK123400), BLR26 (MK123401), and BLR35 (MK123402).According to biochemical tests, BLR5 was oxidase test positive, which is considered as Bacillus proteolyticus MK123398 and BLR16 was oxidase test negative, which is considered Bacillus wiedmannii MK123399.

The phylogenetic tree clearly showed that the strains BLR21 and BLR26 could be divided into two related clades, P. plecoglossicida MK123400 which belonged to one clade was closely related to $P$. plecoglossicida strain NR 024662.1 (GenBank accession).

P. cedrina MK123401 made the other clade that comprised the reference strain P. cedrina NR_024912.1. These results were supported by the BLASTn search analysis against published 16S rRNA gene sequences in the GenBank database, figure (2). 


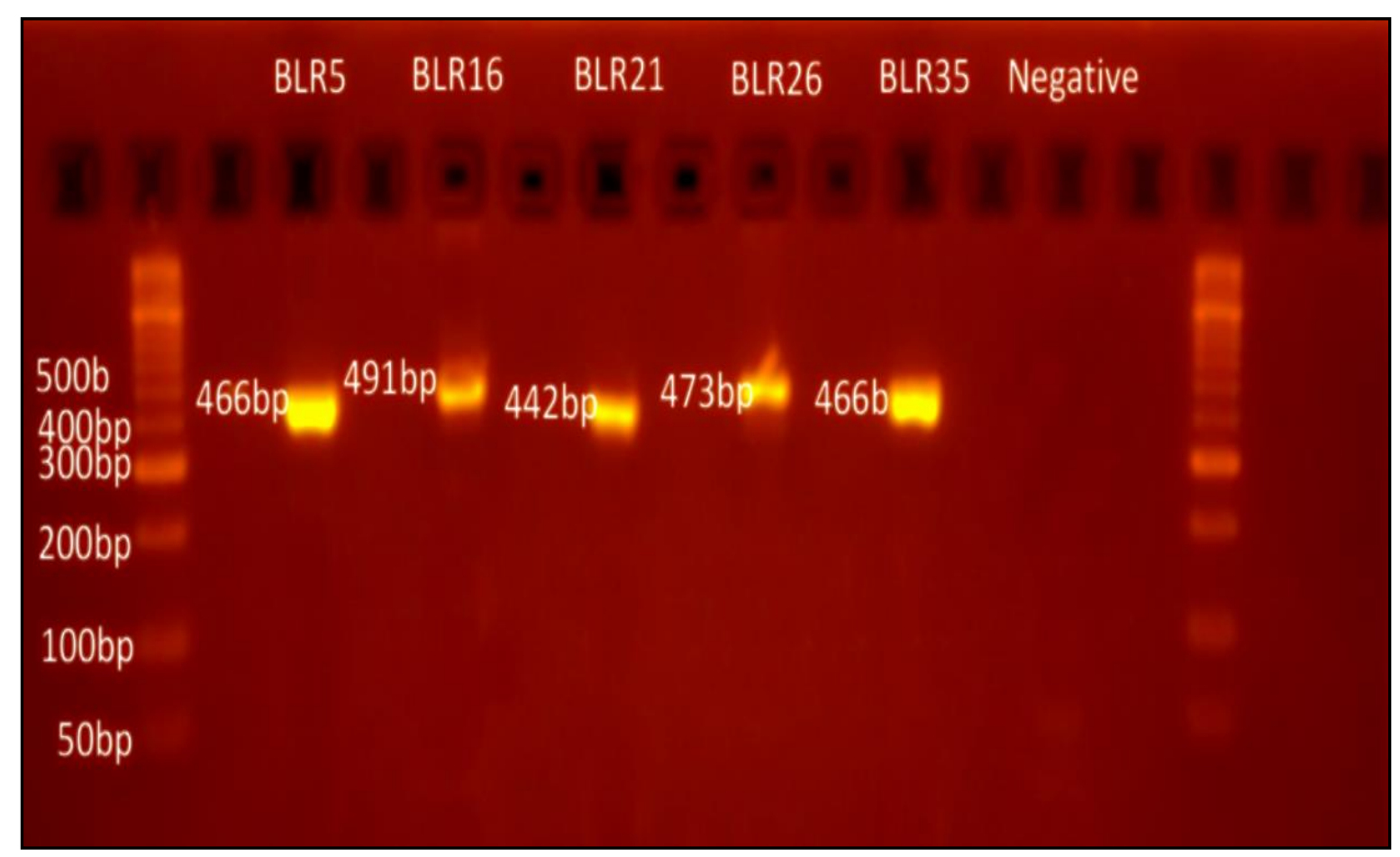

Figure (1): Agarose gel electrophoresis (1.2\%) analysis of the amplified 16S DNA sequences, from five bacterial isolates (BLR5, BLR16, BLR21, BLR26, BLR35) . Lane 1, 15, 100bp Molecular ladder

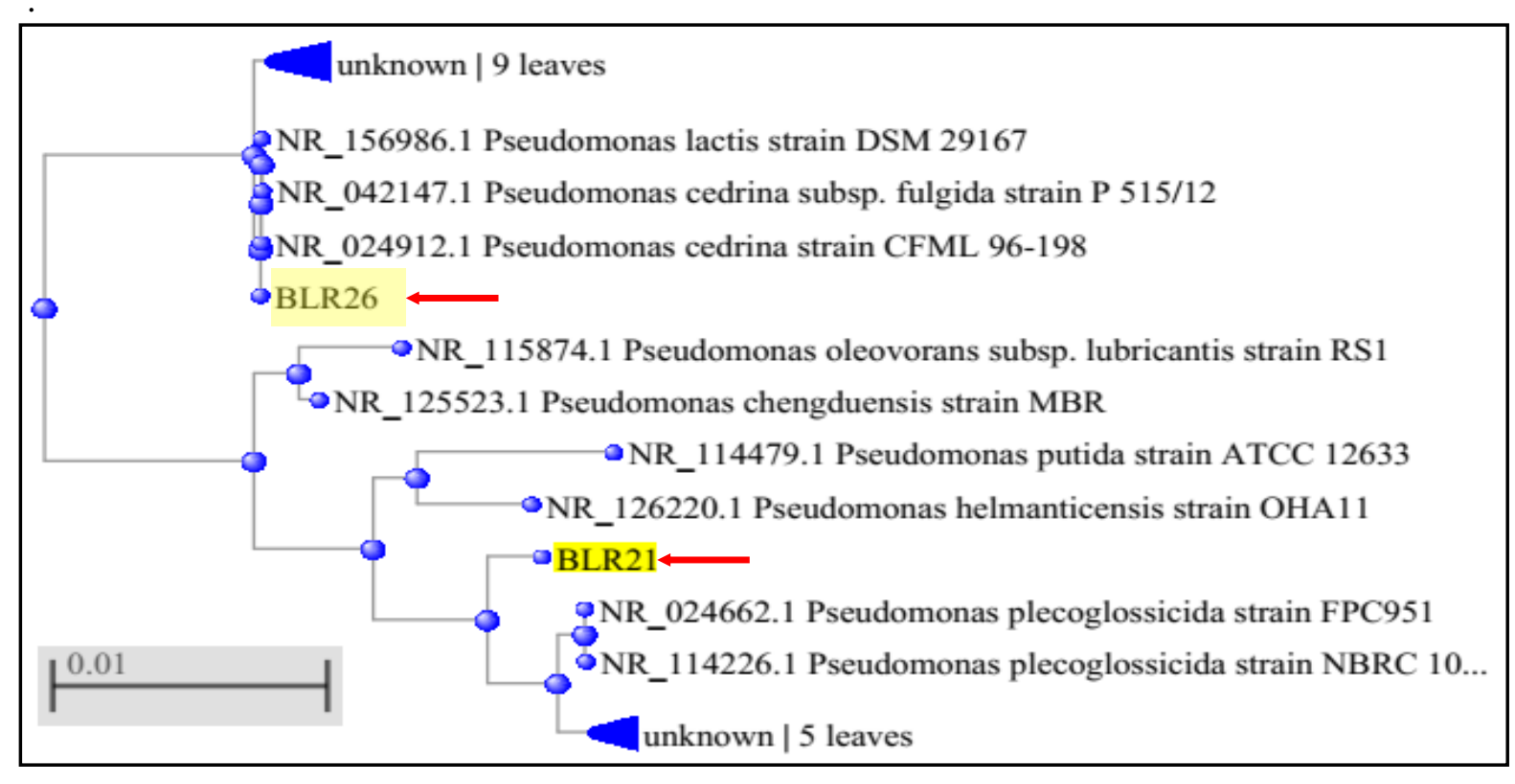

Fig. (2): Phylogenetic tree of BLR21 and BLR26 isolates https://blast.ncbi.nlm.nih.gov/blast/treeview 
Regarding Bacillus species, the phylogenetic tree also showed that strains BLR5 (B. proteolyticus MK123398) and BLR16 (B. wiedmannii MK123399) were very closed related to B. proteolyticus NR_157735.1. Strain BLR35 (B. xiamenensis MK123402) belonged to another clade which was relatively far away from strains BLR5 and BLR16 and were closely related to B. xiamenensis NR_148244.1 and B. stratosphericus NR_042336.1, figure (3)

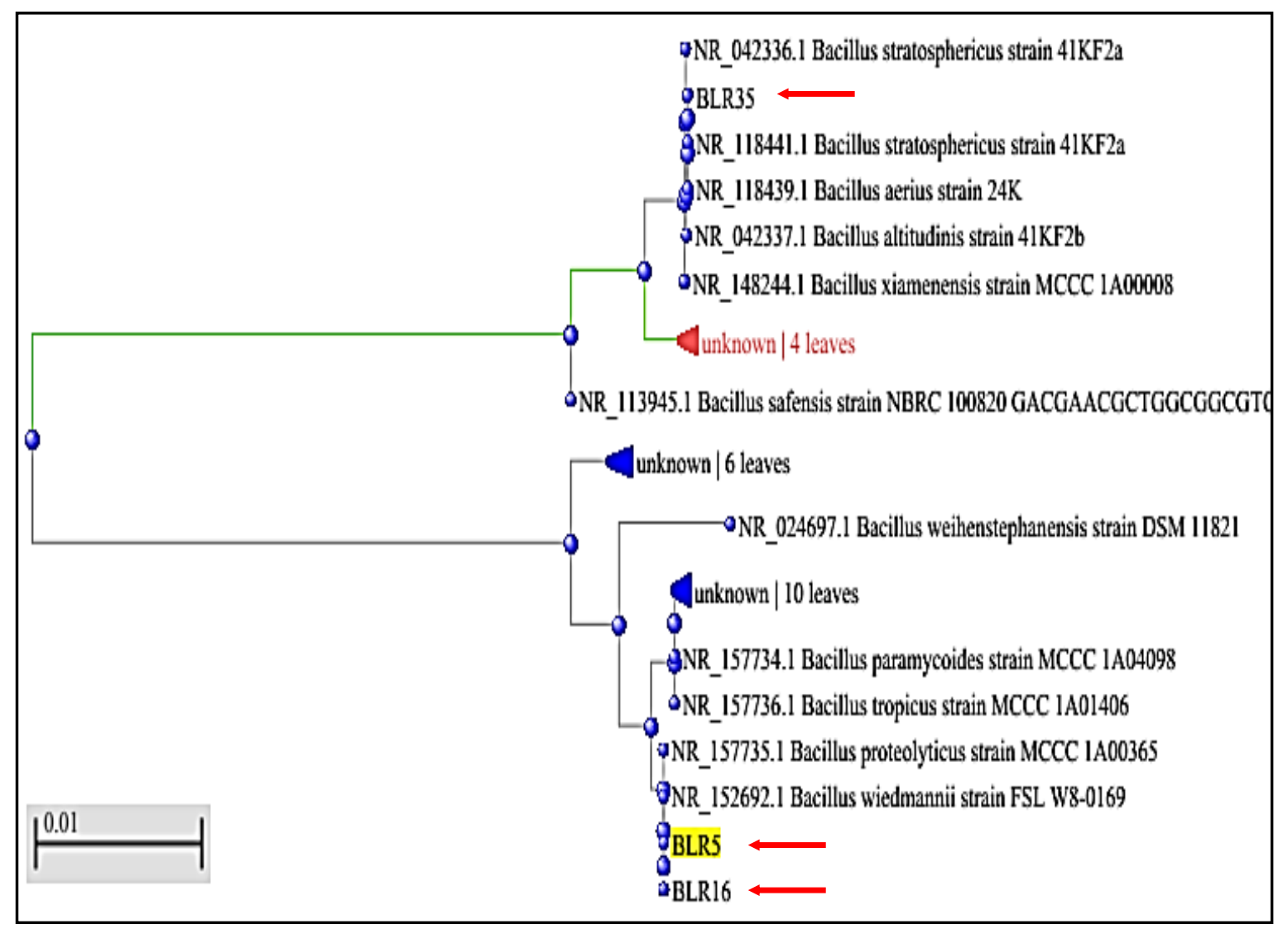

Fig. (3): Phylogenetic tree of BLR5, BLR16, and BLR35 isolates https://blast.ncbi.nlm.nih.gov/blast/treeview. 
Table (1): Charactarization and growth promoting traits of promising rhizosphere bacterial isolates.

\begin{tabular}{|c|c|c|c|c|c|c|c|c|c|c|c|c|}
\hline Test & 2 & 4 & 5 & 6 & 7 & 8 & 9 & 10 & 11 & 12 & 13 & 15 \\
\hline Gram reaction & + & - & + & - & - & + & + & - & + & - & - & - \\
\hline Catalase & + & - & + & + & - & + & + & + & + & - & - & + \\
\hline MR & + & - & - & - & - & + & - & - & + & - & - & - \\
\hline V-P & + & - & - & - & - & + & - & - & - & - & - & - \\
\hline Starch Hydr & + & - & - & - & - & + & - & - & - & - & - & - \\
\hline Motility & - & + & + & - & + & - & + & - & + & + & + & + \\
\hline Pigment & - & - & - & - & + & - & - & + & - & + & - & + \\
\hline Lecithinase & + & - & - & - & - & + & - & - & - & - & - & - \\
\hline Oxidase & - & + & + & - & + & - & - & - & - & - & - & - \\
\hline MacConkey & - & - & - & - & + & - & - & + & - & + & + & + \\
\hline Hemolysis & $\beta$ & $\gamma$ & $\Gamma$ & $\alpha$ & $\gamma$ & $\beta$ & $\alpha$ & $\gamma$ & $\alpha$ & $\gamma$ & $\gamma$ & $\gamma$ \\
\hline Citrate & - & - & + & - & + & - & - & + & - & + & + & + \\
\hline \multirow[t]{2}{*}{ IAA $\mu \mathrm{g} / \mathrm{ml}$} & 6.0 & 7.5 & 14.0 & 11.5 & 4.0 & 2.5 & 12.5 & 7.0 & 18.5 & 2.5 & 0.5 & 4.0 \\
\hline & \pm 0.58 & \pm 0.33 & \pm 0.28 & \pm 0.37 & \pm 0.70 & \pm 0.16 & \pm 0.82 & \pm 0.30 & \pm 0.15 & \pm 0.18 & \pm 0.01 & \pm 0.61 \\
\hline $\mathrm{ZnCO}_{3}$ solub. & - & - & - & - & + & - & - & - & - & - & + & - \\
\hline ZnO solub. & - & - & - & - & - & - & - & - & - & - & - & - \\
\hline Phos. Solub. & - & + & + & - & + & - & - & + & - & - & - & + \\
\hline $\mathrm{ACC}$ & - & + & + & + & + & - & + & + & - & - & + & + \\
\hline Phytase & 930 & 480 & 892 & 1780 & 468 & 468 & 660 & 416 & 2000 & 488 & 460 & 476 \\
\hline \multirow[t]{2}{*}{$\boldsymbol{\mu}$ mol. P. ml- ${ }^{-1} \mathrm{hrs}^{-1}$} & \pm 8.82 & \pm 13.24 & \pm 10.4 & \pm 16.11 & \pm 7.61 & \pm 3.14 & \pm 2.42 & \pm 6.80 & \pm 5.51 & \pm 10.2 & \pm 4.80 & \pm 6.62 \\
\hline & & & 3 & & & & & & & 3 & & \\
\hline
\end{tabular}

Values are mean $\pm \operatorname{SD}(n=3)$. 
Table (1): Charactarization and growth promoting traits of promising rhizosphere bacterial isolates (Cont.).

\begin{tabular}{|c|c|c|c|c|c|c|c|c|c|c|c|c|}
\hline Test & 16 & 18 & 19 & 21 & 22 & 23 & 24 & 26 & 30 & 32 & 33 & 35 \\
\hline Gram reaction & + & + & - & - & + & + & + & - & - & - & - & + \\
\hline Catalase & + & + & + & + & + & - & + & + & + & + & - & + \\
\hline MR & + & - & - & - & - & - & - & - & - & - & - & - \\
\hline V-P & + & - & + & - & + & - & - & - & - & - & - & - \\
\hline Starch Hydr & - & - & - & - & + & - & - & - & - & - & + & - \\
\hline Motility & - & + & - & + & - & - & - & + & + & + & - & + \\
\hline Pigment & - & - & - & + & - & - & - & - & + & + & + & - \\
\hline Lecithinase & - & - & - & - & + & - & - & + & - & - & - & - \\
\hline Oxidase & - & - & - & + & - & - & - & + & + & - & + & - \\
\hline MacConkey & - & - & - & + & - & - & - & + & + & + & + & - \\
\hline Hemolysis & $\alpha$ & $\gamma$ & $\alpha$ & $\gamma$ & $\beta$ & $\gamma$ & $\gamma$ & $\gamma$ & $\gamma$ & $\gamma$ & $\gamma$ & $\gamma$ \\
\hline Citrate & - & - & + & + & + & + & + & - & + & + & + & + \\
\hline IAA $\mu \mathrm{g} / \mathrm{ml}$ & 12.0 & 13.0 & 13.0 & 9.0 & 4.0 & 22.0 & 5.2 & 3.0 & 8.0 & 6.5 & 17.0 & 3.1 \\
\hline & \pm 0.66 & \pm 0.57 & \pm 0.28 & \pm 0.28 & \pm 0.21 & \pm 0.85 & \pm 0.47 & \pm 0.41 & \pm 0.75 & \pm 0.66 & \pm 0.05 & \pm 0.81 \\
\hline $\mathrm{ZnCO}_{3}$ solub. & - & - & - & + & - & - & - & - & + & + & - & - \\
\hline ZnO solub. & + & - & - & - & - & + & - & - & - & - & - & + \\
\hline Phos. Solub. & - & - & + & + & - & - & - & + & - & + & - & + \\
\hline $\mathrm{ACC}$ & - & + & + & - & + & + & + & + & - & - & + & + \\
\hline Phytase & 788 & 788 & 512 & 1104 & 492 & 2000 & 532 & 1268 & 448 & 464 & 1180 & 928 \\
\hline$\mu$ mol. P. ml ${ }^{-1} h^{-1}$ & \pm 2.53 & \pm 1.10 & \pm 8.24 & \pm 11.7 & \pm 3.52 & \pm 4.20 & \pm 1.74 & \pm 15.3 & \pm 1.43 & \pm 3.91 & \pm 5.84 & \pm 2.80 \\
\hline
\end{tabular}

Values are mean $\pm \operatorname{SD}(\mathrm{n}=3)$. 
Table (2): 16S rDNA gene sequence similarities of isolated bacteria showing GenBank accession numbers.

\begin{tabular}{cccc}
\hline Isolate No. & Closest species & sequence identity & Accession no \\
\cline { 3 - 4 } BLR5 & Bacillus proteolyticus & $466 / 466(100 \%)$ & NR_157735.1 \\
BLR16 & Bacillus wiedmannii & $466 / 466(100 \%)$ & NR_152692.1 \\
BLR21 & Pseudomonas plecoglossicidan & $440 / 442(99 \%)$ & NR_024662.1 \\
BLR26 & Pseudomonas cedrina & $470 / 473(99 \%)$ & NR_024912.1 \\
BLR35 & Bacillus xiamenensis & $466 / 466(100 \%)$ & NR_148244.1 \\
\hline
\end{tabular}

\section{Evaluation of plant growth promoting activities}

Four consortia showed significant elevation in root length compared to control seedlings. consortium B. proteolyticus MK123398 and B. wiedmannii MK123399 and B. xiamenensis MK123402 showed the highest record, Table (3). Ten consortia showed significant increase in shoot height compared to control, and the highest significant result was afforded by consortium $P$. plecoglossicida MK123400 and P. cedrina MK123401, Table (3).

Only four consortia showed significant increase in leaves number per plant. consortium $B$. proteolyticus MK123398 and B. xiamenensis MK123402 showed the highest significant value of leaves number per plant, while leaf surface area was significantly increased in twelve formulas, as compared to uninoculated control. consortium B. proteolyticus MK123398 and B. xiamenensis MK123402 showed the highest significant value of leaf surface area, Table (3). Three consortia showed significant increase in fresh weight. The highest significant value $(55.00 \mathrm{~g})$ was afforded by consortium B. proteolyticus MK123398 and B. xiamenensis MK123402 compared to control seedlings (30.00 g). However, the least fresh weight was observed with consortium $B$. wiedmannii MK123399 and B. xiamenensis MK123402, Table (4).

Regarding dry weights, there were three consortia that induced significant increase compared to control seedlings. consortium (B. proteolyticus MK123398 + B. xiamenensis MK123402) afforded the highest significant value, Table (4). Result is also revealed that there are no significant variations in total nitrogen percentages between treated plants and control, Table (4).

\section{Best performance ranking of PGPR consortia}

From the previous data obtained, bacterial consortia can be ranked according to their performance in terms of plant growth induction. Performance descending ranks of consortia for 
each tested growth trait (in triplicate) were examined. Summation of growth trait numerical ranks were established for each bacterial consortium. The best consortium acquired the lowest summation values of numerical ranks, which was judged by significant differences from control numerical ranks summation, Table (5). Accordingly, six consortia: P. plecoglossicida MK123400 and $P$. cedrina MK123401, B. proteolyticus MK123398 and B. xiamenensis MK123402, B. proteolyticus MK123398 and B. wiedmannii MK123399 and B. xiamenensis MK123402, B. proteolyticus MK123398 and P. plecoglossicida MK123400 and B. xiamenensis MK123402, B. wiedmannii MK123399, and B. wiedmannii MK123399 and P. plecoglossicida MK123400 showed significant differences respectively in their ranks compared to control rank, which means that these consortia harbors the best promising for plant growth promotion for Phaseolus vulgaris plant.

\section{Discussion}

The use of PGPR to enhance crops is an environment friendly approach and an effective alternative to toxic chemical fertilizers. Microorganisms harbor several biological activities of agricultural interest, that practically, make them attractive bio-fertilizing agents, for this, the enzymatic tests play a crucial role in the microbial screening [30].

This study assessed for the first time the effect of native plant growth promoting rhizobacteria on the growth of Phaseolus vulgaris seedlings in Gaza strip, and according to the plant growth promoting traits, five PGPR isolated from Phaseolus vulgaris rhizosphere were selected as promising bioinoculants which belong to the genera Bacillus (three isolates), followed by Pseudomonas (two isolates). This result is comparable to numerous studies reported that the most representative genera are Pseudomonas, Enterobacter, Clostridium, Arthrobacter, Achromobacter, Micrococcus, Flavobacterium, Azospirillum, Azotobacter and Bacillus, with the latter being the most common group of bacteria isolated from soil and other environments [31-33].

The results of this research revealed that the five promising PGPR exhibited multiple PGP traits in vitro. They showed approximately the highest phytase enzyme production. Interestingly, our results were compatible with other studies which revealed that phytase-producing rhizobacteria (PPB) not only harbor the ability to mineralize phytate but also harbor other PGPR activities such as the production of indole acetic acid, siderophore, volatile organic compounds, and ammonia [34,35].Results confirmed that, consortium P. plecoglossicida MK123400 and P. cedrina MK123401 showed the higher phytase producers among the 5 selected isolates, which supposedly focus research attentions on the role of this enzyme in plant growth stimulation. 
Synchronous inoculation of Phaseolus vulgaris seeds with P. plecoglossicida MK123400 and P. cedrina MK123401, significantly increased plants growth better than the other 18 tested consortia. Goryluk-Salmonowicz et al., (2018) observed that the most beneficial effect on root growth of triticale seedlings was found for $P$. cedrina N2-1a strain, which is also compatible with

Table (3): Effect of selected rhizobacteria consortia inoculation on growth parameters of Phaseolus vulgari

\begin{tabular}{|c|c|c|c|c|c|}
\hline No & $\begin{array}{l}\text { Bacterial } \\
\text { consortium }\end{array}$ & Root length in cm & $P$ value & Shoot height in $\mathrm{cm}$ & $P$ value \\
\hline 1 & BLR5 & $16.00 \pm 1.50$ & 0.291 & $23.00 \pm 0.63$ & 1.000 \\
\hline 2 & BLR16 & $22.00 \pm 1.23$ & 0.291 & $36.83 \pm 1.09$ & $<0.001^{*}$ \\
\hline 3 & BLR21 & $16.00 \pm 1.56$ & 0.291 & $26.00 \pm 1.00$ & 0.402 \\
\hline 4 & BLR26 & $19.67 \pm 0.91$ & 1.000 & $32.16 \pm 2.14$ & $<0.001^{*}$ \\
\hline 5 & BLR35 & $24.00 \pm 1.58$ & $0.002 *$ & $28.53 \pm 1.44$ & $0.001 *$ \\
\hline 6 & $\operatorname{BLR}(5+16)$ & $14.50 \pm 1.02$ & 0.008 & $24.00 \pm 0.77$ & 1.000 \\
\hline 7 & $\operatorname{BLR}(5+21)$ & $20.00 \pm 1.50$ & 1.000 & $25.33 \pm 1.26$ & 0.804 \\
\hline 8 & $\operatorname{BLR}(5+26)$ & $15.10 \pm 1.24$ & 0.031 & $26.50 \pm 1.34$ & 0.173 \\
\hline 9 & BLR $(5+35)$ & $20.00 \pm 1.67$ & 1.000 & $33.10 \pm 2.24$ & $<0.001 *$ \\
\hline 10 & BLR (16+21) & $19.33 \pm 0.91$ & 1.000 & $29.83 \pm 1.12$ & $<0.001^{*}$ \\
\hline 11 & $\operatorname{BLR}(16+35)$ & $17.77 \pm 0.74$ & 0.999 & $20.17 \pm 1.29$ & 0.505 \\
\hline 12 & $\operatorname{BLR}(21+26)$ & $25.00 \pm 1.24$ & $<0.001^{*}$ & $39.00 \pm 1.35$ & $<0.001 *$ \\
\hline 13 & $\operatorname{BLR}(21+35)$ & $18.50 \pm 0.79$ & 1.000 & $27.90 \pm 1.13$ & $0.006^{*}$ \\
\hline 14 & $\operatorname{BLR}(5+16+21)$ & $20.00 \pm 1.20$ & 1.000 & $28.00 \pm 1.50$ & $0.005^{*}$ \\
\hline 15 & $\operatorname{BLR}(5+16+35)$ & $35.00 \pm 1.61$ & $<0.001^{*}$ & $38.50 \pm 0.91$ & $<0.001^{*}$ \\
\hline 16 & $\operatorname{BLR}(5+21+26)$ & $15.67 \pm 1.29$ & 0.072 & $24.40 \pm 1.05$ & 1.000 \\
\hline 17 & $\operatorname{BLR}(5+21+35)$ & $33.00 \pm 0.74$ & $<0.001^{*}$ & $33.23 \pm 1.44$ & $<0.001 *$ \\
\hline 18 & $\operatorname{BLR}(16+21+35)$ & $14.40 \pm 0.90$ & $<0.001$ & $18.50 \pm 0.90$ & 0.018 \\
\hline 19 & $\operatorname{BLR}(5+16+21+35)$ & $17.50 \pm 0.83$ & 0.992 & $22.50 \pm 0.91$ & 1.000 \\
\hline 20 & control & $19.00 \pm 1.37$ & Reference & $23.00 \pm 1.60$ & Reference \\
\hline
\end{tabular}


Table (3): Effect of selected rhizobacteria consortia inoculation on growth parameters of Phaseolus vulgaris (Cont.).

\begin{tabular}{|c|c|c|c|c|c|}
\hline No & $\begin{array}{l}\text { Bacterial } \\
\text { consortium }\end{array}$ & Leaf No./plant & $P$ value & Leaf $S$. area in $\mathrm{cm}^{2}$ & $P$ value \\
\hline 1 & BLR5 & $26.00 \pm 1.29$ & 1.000 & $43.39 \pm 0.95$ & $<0.001$ \\
\hline 2 & BLR16 & $24.33 \pm 0.90$ & 0.951 & $63.33 \pm 1.03$ & 0.477 \\
\hline 3 & BLR21 & $30.80 \pm 1.25$ & $0.001 *$ & $76.00 \pm 1.80$ & $<0.001 *$ \\
\hline 4 & BLR26 & $24.67 \pm 0.70$ & 0.995 & $75.67 \pm 1.15$ & $<0.001 *$ \\
\hline 5 & BLR35 & $23.00 \pm 1.14$ & 0.184 & $47.00 \pm 1.51$ & $<0.001$ \\
\hline 6 & $\operatorname{BLR}(5+16)$ & $25.00 \pm 1.00$ & 1.000 & $64.98 \pm 1.66$ & $0.030^{*}$ \\
\hline 7 & BLR (5+ 21) & $26.00 \pm 1.64$ & 1.000 & $73.00 \pm 0.74$ & $<0.001 *$ \\
\hline 8 & BLR (5+26) & $26.00 \pm 1.48$ & 1.000 & $71.00 \pm 0.90$ & $<0.001 *$ \\
\hline 9 & BLR $(5+35)$ & $43.00 \pm 1.68$ & $<0.001 *$ & $105.00 \pm 2.77$ & $<0.001 *$ \\
\hline 10 & BLR (16+21) & $26.67 \pm 0.67$ & 1.000 & $74.20 \pm 0.94$ & $<0.001 *$ \\
\hline 11 & $\operatorname{BLR}(16+35)$ & $22.00 \pm 0.95$ & 0.014 & $74.14 \pm 2.06$ & $<0.001 *$ \\
\hline 12 & $\operatorname{BLR}(21+26)$ & $39.00 \pm 1.02$ & $<0.001^{*}$ & $101.1 \pm 1.97$ & $<0.001 *$ \\
\hline 13 & $\operatorname{BLR}(21+35)$ & $30.00 \pm 1.42$ & $0.013^{*}$ & $49.19 \pm 1.26$ & $<0.001$ \\
\hline 14 & $\operatorname{BLR}(5+16+21)$ & $23.00 \pm 1.18$ & 0.184 & $73.00 \pm 1.87$ & $<0.001 *$ \\
\hline 15 & $\operatorname{BLR}(5+16+35)$ & $29.33 \pm 0.65$ & 0.084 & $78.50 \pm 1.08$ & $<0.001 *$ \\
\hline 16 & $\operatorname{BLR}(5+21+26)$ & $19.33 \pm 0.89$ & $<0.001$ & $50.00 \pm 1.39$ & $<0.001$ \\
\hline 17 & $\operatorname{BLR}(5+21+35)$ & $20.00 \pm 0.82$ & $<0.001$ & $79.00 \pm 2.12$ & $<0.001 *$ \\
\hline 18 & $\operatorname{BLR}(16+21+35)$ & $21.00 \pm 1.21$ & 0.001 & $52.50 \pm 1.07$ & $<0.001$ \\
\hline 19 & $\operatorname{BLR}(5+16+21+35)$ & $25.00 \pm 1.21$ & 1.000 & $43.87 \pm 0.59$ & $<0.001$ \\
\hline 20 & control & $26.00 \pm 0.92$ & Reference & $60.00 \pm 1.69$ & Reference \\
\hline
\end{tabular}

- Means of nine replications.

- (*) denotes significant increase of treatment values compared to control measurements at $95 \%$ confidence levels, based on ANOVA (Tukey's test). BLR5 = B. proteolyticus MK123398, BLR16 = B. wiedmannii MK123399, BLR21= P. plecoglossicida MK123400, BLR26 = P. cedrina MK123401, BLR35 = B. xiamenensis MK123402 
Table (4): Effect of selected rhizobacteria consortia inoculatioin on weights and nitrogen contents of Phaseolus vulgaris.

\begin{tabular}{|c|c|c|c|c|c|c|}
\hline No & $\begin{array}{l}\text { Bacterial } \\
\text { consortium }\end{array}$ & $\begin{array}{c}\text { Fresh } \\
\text { weight in } \\
\text { gm }\end{array}$ & $P$ value & $\begin{array}{c}\text { Dry } \\
\text { weight in } \\
\text { gm }\end{array}$ & $P$ value & Nitrogen \% \\
\hline 1 & BLR5 & $18.66 \pm 0.40$ & $<0.001$ & $1.60 \pm 0.02$ & $<0.001$ & $3.43 \pm 0.02$ \\
\hline 2 & BLR16 & $28.33 \pm 0.99$ & 0.936 & $4.12 \pm 0.41$ & 0.435 & $3.53 \pm 0.02$ \\
\hline 3 & BLR21 & $26.95 \pm 0.78$ & 0.204 & $2.66 \pm 0.18$ & 0.856 & $3.65 \pm 0.30$ \\
\hline 4 & BLR26 & $20.00 \pm 1.95$ & $<0.001$ & $2.69 \pm 0.10$ & 0.894 & $3.53 \pm 0.13$ \\
\hline 5 & BLR35 & $20.00 \pm 0.65$ & $<0.001$ & $2.72 \pm 0.19$ & 0.928 & $3.41 \pm 0.38$ \\
\hline 6 & BLR (5+16) & $16.53 \pm 0.74$ & $<0.001$ & $1.36 \pm 0.09$ & $<0.001$ & $3.73 \pm 0.24$ \\
\hline 7 & $\operatorname{BLR}(5+21)$ & $20.00 \pm 1.04$ & $<0.001$ & $2.33 \pm 0.15$ & 0.207 & $3.58 \pm 0.17$ \\
\hline 8 & $\operatorname{BLR}(5+26)$ & $22.67 \pm 0.85$ & $<0.001$ & $1.58 \pm 0.10$ & $<0.001$ & $3.81 \pm 0.19$ \\
\hline 9 & $\operatorname{BLR}(5+35)$ & $55.00 \pm 2.00$ & $<0.001 *$ & $6.96 \pm 0.06$ & $<0.001 *$ & $3.63 \pm 0.15$ \\
\hline 10 & BLR (16+21) & $25.16 \pm 1.15$ & 0.002 & $2.66 \pm 0.22$ & 0.854 & $3.59 \pm 0.14$ \\
\hline 11 & $\operatorname{BLR}(16+35)$ & $13.33 \pm 1.05$ & $<0.001$ & $1.54 \pm 0.13$ & $<0.001$ & $3.57 \pm 0.10$ \\
\hline 12 & BLR $(21+26)$ & $50.00 \pm 1.94$ & $<0.001 *$ & $5.92 \pm 0.04$ & $<0.001 *$ & $3.69 \pm 0.01$ \\
\hline 13 & $\operatorname{BLR}(21+35)$ & $22.21 \pm 0.92$ & $<0.001$ & $2.04 \pm 0.04$ & 0.021 & $3.61 \pm 0.36$ \\
\hline 14 & $\operatorname{BLR}(5+16+21)$ & $27.00 \pm 1.18$ & 0.226 & $2.04 \pm 0.12$ & 0.110 & $3.52 \pm 0.12$ \\
\hline 15 & $\operatorname{BLR}(5+16+35)$ & $35.00 \pm 1.59$ & $0.001 *$ & $4.93 \pm 0.15$ & $<0.001 *$ & $3.66 \pm 0.07$ \\
\hline 16 & $\operatorname{BLR}(5+21+26)$ & $16.86 \pm 0.63$ & $<0.001$ & $1.71 \pm 0.14$ & 0.001 & $3.83 \pm 0.16$ \\
\hline 17 & $\operatorname{BLR}(5+21+35)$ & $30.00 \pm 1.39$ & 1.000 & $3.40 \pm 0.11$ & 1.000 & $3.50 \pm 0.24$ \\
\hline 18 & $\operatorname{BLR}(16+21+35)$ & $15.87 \pm 0.72$ & $<0.001$ & $1.16 \pm 0.10$ & $<0.001$ & $3.48 \pm 0.05$ \\
\hline 19 & $\operatorname{BLR}(5+16+21+35)$ & $18.39 \pm 0.94$ & $<0.001$ & $1.67 \pm 0.14$ & 0.001 & $3.33 \pm 0.10$ \\
\hline 20 & control & $30.00 \pm 0.88$ & Reference & $3.29 \pm 0.58$ & Reference & $3.63 \pm 0.33$ \\
\hline
\end{tabular}

- Means of nine replications.

- (*) denotes significant increase of treatment values compared to control measurements at $95 \%$ confidence levels, based on ANOVA (Tukey's test).

BLR5 = B. proteolyticus MK123398, BLR16 = B. wiedmannii MK123399, BLR21= P. plecoglossicida MK123400, BLR26 = P. cedrina MK123401, BLR35 = B. xiamenensis MK1 
Table (5): Ranks of bacterial inoculums for each tested plant growth trait and their rank summation.

\begin{tabular}{|c|c|c|c|c|c|c|c|c|c|}
\hline Bacterial inoculum & $\begin{array}{l}\text { Root } \\
\text { length }\end{array}$ & $\begin{array}{l}\text { Shoot } \\
\text { Length }\end{array}$ & $\begin{array}{l}\text { Leaf } \\
\text { No }\end{array}$ & $\begin{array}{l}\text { Leaf } \\
\text { Area }\end{array}$ & $\begin{array}{l}\text { Fresh } \\
\text { weight }\end{array}$ & $\begin{array}{c}\text { Dry } \\
\text { weight }\end{array}$ & $\begin{array}{l}\text { Sum. of } \\
\text { ranks }\end{array}$ & $\begin{array}{l}\text { Mean } \\
\text { of } \\
\text { ranks }\end{array}$ & $P$ value \\
\hline \multirow{3}{*}{ B. proteolyticus MK123398 } & 15 & 17 & 9 & 20 & 16 & 17 & 94 & \multirow{3}{*}{92.33} & \multirow{3}{*}{$<0.001$} \\
\hline & 16 & 17 & 7 & 20 & 15 & 18 & 93 & & \\
\hline & 16 & 16 & 8 & 20 & 14 & 16 & 90 & & \\
\hline \multirow{3}{*}{ B. wiedmannii MK123399 } & 5 & 3 & 14 & 13 & 6 & 4 & 45 & \multirow{3}{*}{45.00} & \multirow{3}{*}{$<0.001^{*}$} \\
\hline & 5 & 3 & 14 & 13 & 6 & 4 & 45 & & \\
\hline & 5 & 3 & 14 & 13 & 6 & 4 & 45 & & \\
\hline \multirow{3}{*}{$\begin{array}{c}\text { P. plecoglossicida } \\
\text { MK123400 }\end{array}$} & 16 & 12 & 3 & 5 & 8 & 10 & 54 & \multirow{3}{*}{53.67} & \multirow{3}{*}{0.208} \\
\hline & 15 & 13 & 4 & 5 & 8 & 9 & 54 & & \\
\hline & 17 & 11 & 5 & 6 & 7 & 7 & 53 & & \\
\hline \multirow{3}{*}{ P. cedrina MK123401 } & 9 & 5 & 13 & 6 & 12 & 9 & 54 & \multirow{3}{*}{53.67} & \multirow{3}{*}{0.208} \\
\hline & 9 & 6 & 13 & 7 & 12 & 8 & 55 & & \\
\hline & 7 & 4 & 12 & 5 & 15 & 9 & 52 & & \\
\hline \multirow{3}{*}{ B. xiamenensis MK123402 } & 4 & 8 & 16 & 18 & 14 & 7 & 67 & \multirow{3}{*}{67.67} & \multirow{3}{*}{0.046} \\
\hline & 4 & 10 & 15 & 18 & 14 & 7 & 68 & & \\
\hline & 4 & 8 & 16 & 18 & 12 & 10 & 68 & & \\
\hline \multirow{3}{*}{$\begin{array}{l}\text { B. proteolyticus MK123398 } \\
\text { B. wiedmannii MK123399 }\end{array}$} & 19 & 15 & 12 & 12 & 18 & 19 & 95 & \multirow{3}{*}{94.33} & \multirow{3}{*}{$<0.001$} \\
\hline & 19 & 16 & 11 & 12 & 18 & 19 & 95 & & \\
\hline & 20 & 14 & 11 & 12 & 18 & 18 & 93 & & \\
\hline \multirow{4}{*}{$\begin{array}{c}\text { B. proteolyticus MK123398 } \\
\text { P. plecoglossicida }\end{array}$} & 7 & 13 & 7 & 10 & 13 & 8 & 58 & \multirow{4}{*}{62.33} & \multirow{4}{*}{1.000} \\
\hline & & & & & & & & & \\
\hline & 7 & 12 & 8 & 10 & 13 & 11 & 61 & & \\
\hline & 9 & 13 & 10 & 8 & 13 & 15 & 68 & & \\
\hline
\end{tabular}




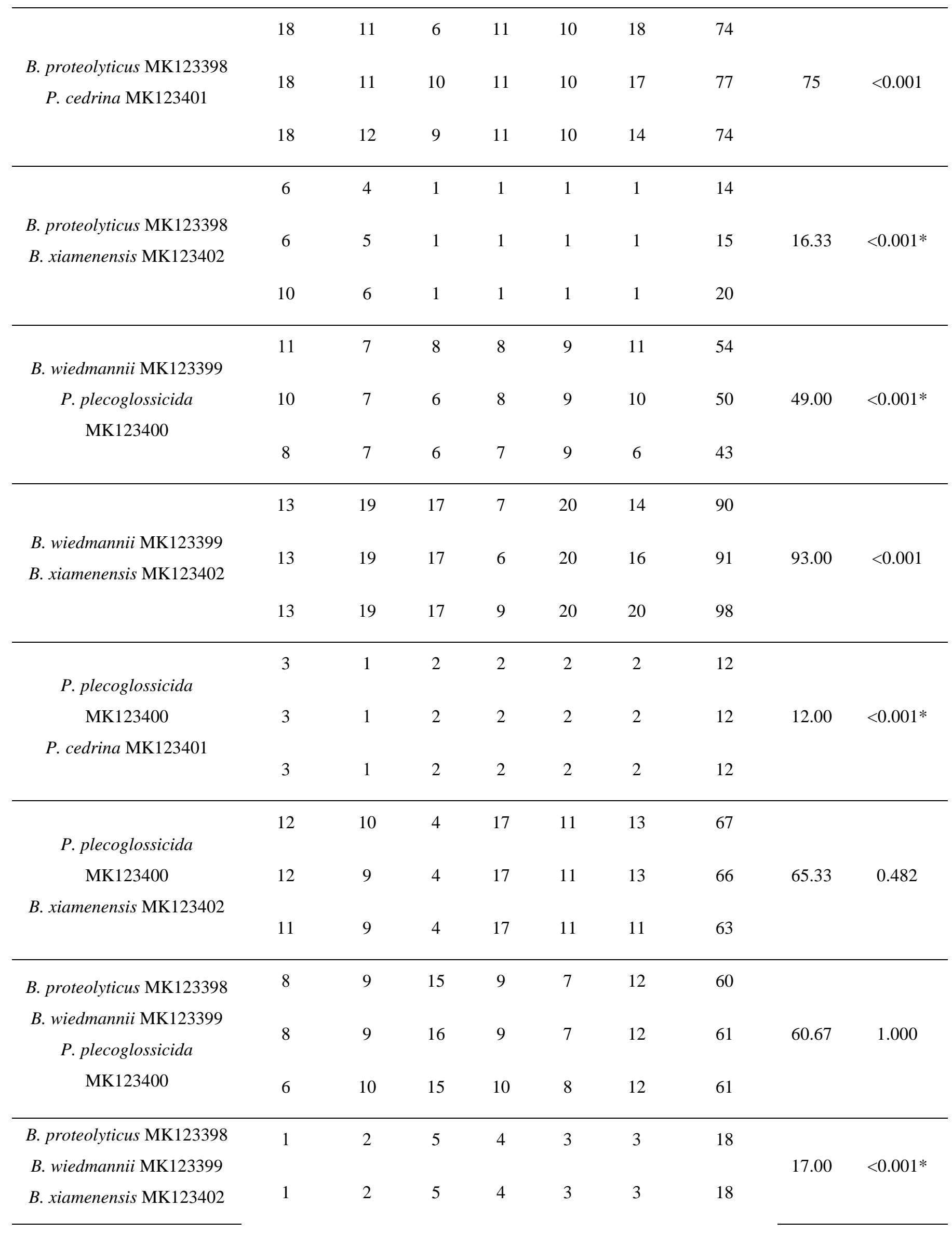




\begin{tabular}{|c|c|c|c|c|c|c|c|c|c|}
\hline & 1 & 2 & 3 & 3 & 3 & 3 & 15 & & \\
\hline B. proteolyticus MK123398 & 17 & 14 & 20 & 16 & 17 & 15 & 99 & & \\
\hline $\begin{array}{c}\text { P. plecoglossicida } \\
\text { MK123400 }\end{array}$ & 17 & 14 & 20 & 16 & 17 & 14 & 98 & 99.00 & $<0.001$ \\
\hline P. cedrina MK123401 & 15 & 15 & 20 & 16 & 17 & 17 & 100 & & \\
\hline B. proteolyticus MK123398 & 2 & 6 & 19 & 3 & 4 & 5 & 39 & & \\
\hline $\begin{array}{c}\text { P. plecoglossicida } \\
\text { MK123400 }\end{array}$ & 2 & 4 & 19 & 3 & 5 & 5 & 40 & 41.33 & $<0.001 *$ \\
\hline B. xiamenensis MK123402 & 2 & 5 & 19 & 4 & 5 & 8 & 45 & & \\
\hline B. wiedmannii MK123399 & 20 & 20 & 18 & 15 & 19 & 20 & 112 & & \\
\hline $\begin{array}{c}\text { P. plecoglossicida } \\
\text { MK123400 }\end{array}$ & 20 & 20 & 18 & 15 & 19 & 20 & 112 & 111.33 & $<0.001$ \\
\hline B. xiamenensis MK123402 & 19 & 20 & 18 & 15 & 19 & 19 & 110 & & \\
\hline $\begin{array}{l}\text { B. proteolyticus MK123398 } \\
\text { B. wiedmannii MK123399 }\end{array}$ & 14 & 18 & 11 & 19 & 15 & 16 & 93 & & \\
\hline P. plecoglossicida & 14 & 18 & 12 & 19 & 16 & 15 & 94 & 93.00 & $<0.001$ \\
\hline $\begin{array}{c}\text { MK123400 } \\
\text { B. xiamenensis MK123402 }\end{array}$ & 14 & 17 & 13 & 19 & 16 & 13 & 92 & & \\
\hline \multirow{3}{*}{ control } & 10 & 16 & 10 & 14 & 5 & 6 & 61 & & \multirow{3}{*}{ Reference } \\
\hline & 11 & 15 & 9 & 14 & 4 & 6 & 59 & 60.00 & \\
\hline & 12 & 18 & 7 & 14 & 4 & 5 & 60 & & \\
\hline
\end{tabular}

- Means of three replications.

- * denotes significant differences between treatment and control ranks at $95 \%$ confidence levels, based on ANOVA (Tukey's test). 
Yadav, (2017), who considered P. cedrina one of the important plant growth promoting rhizobacteria [36,37].

P. plecoglossicida has not been tested as a bio-inoculant on Phaseolus vulgaris, however, Sirvastava et al., (2014) found that P. plecoglossicida PsF610 increased the dry biomass of rose-scented geranium shoots by $38 \%$, roots by $40 \%$, essential oil yield by $39 \%$ and chlorophyll by $28 \%$ over uninoculated controls. Consortium P. plecoglossicida MK123400 and P. cedrina MK123401 enhanced most of plant growth parameters as compared to the single isolates [38]. This might be due to direct and indirect enhancement of plant growth by a variety of mechanisms such as production of growth promoting substances and solubilization of minerals such as phosphorus [39].

Designed upon our scientific research, there were six consortia in plant growth promoting rank, who significantly increased overall plant growth compared to control rank. consortia B. proteolyticus MK123398 and B. xiamenensis MK123402, and B. proteolyticus MK123398 and B. wiedmannii MK123399 and B. xiamenensis MK12340 have the second and third higher significant plant growth promotion rank respectively, which clearly indicates the important role of many Bacillus species to enhance plant growth. This was similar to the work of Masciarelli et al., 2014 [40], who indicated that co-inoculation of soybean plants with Bacillus strains, (capable of producing high levels of auxin, gibberellins and salicylic acid) and natural symbiont B. japonicum altered plant growth parameters and significantly improved nodulation.

Unexpectedly, the present study found some consortia e.g., B. wiedmannii MK123399 and P. plecoglossicida MK123400 and B. xiamenensis MK123402, and B. proteolyticus MK123398 and P. plecoglossicida MK123400 and P. cedrina MK123401 exhibited negative effects on plant growth parameters. The mechanism of these effects deserves further investigation.

The developmental plasticity that characterizes plants, however, allows this strict form to respond to external environmental conditions. Auxin has emerged as a central mediator of these responses and has been shown to act via cell division, cell elongation and cell differentiation [41]. Isolates B. proteolyticus MK123398 and B. wiedmannii MK123399 are 
among the most active IAA producers, which may explain why consortium B. proteolyticus MK123398 and B. wiedmannii MK123399 and B. xiamenensis MK123402 introduced the longest root length as compared to others. Moreover, the ability of those rhizobacteria to produce IAA can be exploited for upgrading root crop plants. Comparable effects of IAA were reported by several investigators upon application of IAA producing Bacillus subtilis as an inoculant on different plants [42].

Non-significant variations in total nitrogen percentage between inoculated plants and uninoculated controls might be due to homogenous genetic constitution of treated seeds as plant nitrogen content largely affected by genetic constitution.

\section{Conclusion}

As the co-inoculation of P. plecoglossicida MK123400 and P. cedrina MK123401 on Phaseolus vulgaris was unprecedented in previous reports, additional efforts should be done on their effects and applications as promising biofertilizers. The obtained results are encouraging and urging us to continue the isolation and selection of native plant growthpromoting rhizobacteria and testing them, in all the possible combinations, on other economically important crops.

\section{References}

[1] H.F. Erbersdobler, C.A. Barth, G. Jahreis," Legumes in human nutrition Nutrient content and protein quality of pulses Fatty acid distribution" Sci. Res. | Overv. 140 Ernaehrungs Umschau Int. 10: (2017). https://doi.org/10.4455/eu.2017.038.

[2] L.C. Van Loon "Plant responses to plant growth-promoting rhizobacteria" Eur. J. Plant Pathol. 119: (2007). https://doi.org/10.1007/s10658-007-9165-1.

[3] A. Sharma, P.L. Kashyap, A.K. Srivastava, Y.K. Bansal, R. Kaushik "Isolation and characterization of halotolerant bacilli from chickpea (Cicer arietinum L.) rhizosphere for plant growth promotion and biocontrol traits" Eur. J. Plant Pathol. 153: (2019). https://doi.org/10.1007/s10658-018-1592-7.

[4] P. Saini, V. Khanna "Evaluation of native rhizobacteria as promoters of plant growth for increased yield in lentil (Lens culinaris)" Recent Res. Sci. Technol. 4: (2012). 
http://updatepublishing.com/journal/index.php/rrst/article/view/881.

[5] S.A. Saiyad, Y.K. Jhala, R. V Vyas "Comparative efficiency of five potash and phosphate solubilizing bacteria and their key enzymes useful for enhancing and improvement of soil fertility" Int. J. Sci. Res. Publ. 5: (2015). www.ijsrp.org

[6] R.J. Cook, L.S. Thomashow, D.M. Weller, D. Fujimoto, M. Mazzola, G. Bangera, D.S. Kim" Molecular mechanisms of defense by rhizobacteria against root disease" Proc. Natl. Acad. Sci. U. S. A. 92: (1995). https://doi.org/10.1073/pnas.92.10.4197.

[7] S.L. Fox, G.W. O’Hara, L. Bräu "Enhanced nodulation and symbiotic effectiveness of Medicago truncatula when co-inoculated with Pseudomonas fluorescens WSM3457 and Ensifer (Sinorhizobium) medicae WSM419" Plant Soil. 348: (2011). https://doi.org/10.1007/s11104-011-0959-8.

[8] K.V.B.R. Tilak, N. Ranganayaki, C. Manoharachari "Synergistic effects of plant-growth promoting rhizobacteria and Rhizobium on nodulation and nitrogen fixation by pigeonpea (Cajanus cajan)" in: Eur. J. Soil Sci., John Wiley \& Sons, Ltd, 2006: pp. 67-71. https://doi.org/10.1111/j.1365-2389.2006.00771.x.

[9] L. Zhou, H. Zheng, Y. Tang, W. Yu, Q. Gong " Eugenol inhibits quorum sensing at subinhibitory concentrations" Biotechnol. Lett. 35: (2013). https://doi.org/10.1007/s10529-0121126-x.

[10] R. Çakmakçi, F. Dönmez, A. Aydin, F. Şahin " Growth promotion of plants by plant growthpromoting rhizobacteria under greenhouse and two different field soil conditions" Soil Biol. Biochem. 38: (2006). https://doi.org/10.1016/j.soilbio.2005.09.019.

[11] S. Zhang, T.L. White, M.C. Martinez, J.A. Mcinroy, J.W. Kloepper, W. Klassen "Evaluation of plant growth-promoting rhizobacteria for control of Phytophthora blight on squash under $\begin{array}{lllll}\text { greenhouse } & \text { conditions" } & \text { (2009).. }\end{array}$ https://doi.org/10.1016/j.biocontrol.2009.10.015.

[12] J. Wang, Q. Li, S. Xu, W. Zhao, Y. Lei, C. Song, Z. Huang " Traits-Based Integration of Multi-Species Inoculants Facilitates Shifts of Indigenous Soil Bacterial Community" Front. Microbiol. 9: (2018). https://doi.org/10.3389/fmicb.2018.01692. 
[13] A.H. Al Hallaq: The impact of soil texture on nitrates leaching into groundwater in the north governorate, Gaza strip: J. Soc. Sci. 38: (2010) .

[14] H. Kesaulya, Baharuddin, B. Zakaria, S.A. Syaiful "Isolation and Physiological Characterization of PGPR from Potato Plant Rhizosphere in Medium Land of Buru Island" Procedia Food Sci. 3: (2015). https://doi.org/10.1016/j.profoo.2015.01.021.

[15] J. Dutta, D. Thakur "Evaluation of multifarious plant growth promoting traits, antagonistic potential and phylogenetic affiliation of rhizobacteria associated with commercial tea plants grown in Darjeeling, India" PLoS One. 12: (2017). https://doi.org/10.1371/journal.pone.0182302.

[16] M.A.-M. Maleki M. A4 - Mostafaee, S. A4 - Mokhtarnejad, L. A4 - Farzaneh, M. "Characterization of Pseudomonas fluorescens strain CV6 isolated from cucumber rhizosphere in Varamin as a potential biocontrol agent" Aust. J. Crop Sci. v. 4: (2010) http://www.cropj.com/.

[17] P.K. Goteti, L.D.A. Emmanuel, S. Desai, M.H.A. Shaik "Prospective zinc solubilising bacteria for enhanced nutrient uptake and growth promotion in maize (Zea mays L.)" Int. J. Microbiol. 2013: (2013). https://doi.org/10.1155/2013/869697.

[18] M. Gupta, S. Kiran, A. Gulati, B. Singh, R. Tewari " Isolation and identification of phosphate solubilizing bacteria able to enhance the growth and aloin-A biosynthesis of Aloe $\begin{array}{lllll}\text { barbadensis } & \text { Miller" }\end{array}$ https://doi.org/10.1016/j.micres.2012.02.004.

[19] A.R. Akhgar, M. Arzanlou, P.A.H.M. Bakker, M. Hamidpour "Characterization of 1Aminocyclopropane-1-Carboxylate (ACC) deaminase-containing pseudomonas spp. in the Rhizosphere of salt-stressed canola" Pedosphere. 24: (2014). https://doi.org/10.1016/S10020160(14)60032-1.

[20] S. Aarab, F.J. Ollero, M. Megías, A. Laglaoui, M. Bakkali, A. Arakrak "Isolation and screening of bacteria from rhizospheric soils of rice fields in Northwestern Morocco for different plant growth promotion (PGP) activities: An in vitro study" 2015. http://www.ijcmas.com .

[21] S.J. Xu, B.S. Kim, Biocontrol of fusarium crown and root rot and promotion of growth of 
tomato by Paenibacillus strains isolated from soil, Mycobiology. 42: (2014). https://doi.org/10.5941/MYCO.2014.42.2.158.

[22] A. Yateem, M.T. Balba, T. Al-Surrayai, B. Al-Mutairi, R. Al-Daher " Isolation of Lactic Acid Bacteria with probiotic potential from camel milk" Int. J. Dairy Sci. 3: (2008) https://doi.org/10.3923/ijds.2008.194.199.

[23] M. Polak-Berecka, A. Waśko, D. Koston " Comparison of different methods for detection of antimicrobial activity of probiotic strains of Lactobacillus rhamnosus against some food spoilage microorganisms" Ann. UMCS, Biol. 64: (2010). https://doi.org/10.2478/v10067010-0002-0.

[24] M.I. Queipo-Ortuño, J. De Dios Colmenero, M. Macias, M.J. Bravo, P. Morata " Preparation of bacterial DNA template by boiling and effect of immunoglobulin $g$ as an inhibitor in realtime PCR for serum samples from patients with brucellosis" Clin. Vaccine Immunol. 15: (2008). https://doi.org/10.1128/CVI.00270-07.

[25] M. Marín, J.M. Garcia-Lechuz, P. Alonso, M. Villanueva, L. Alcalá, M. Gimeno, E. Cercenado, M. Sánchez-Somolinos, C. Radice, E. Bouza " Role of universal 16S rRNA gene PCR and sequencing in diagnosis of prosthetic joint infection" J. Clin. Microbiol. 50: (2012). https://doi.org/10.1128/JCM.00170-11.

[26] O. Stajković, D. Delić, D. Jošić, Đ. Kuzmanović, N. Rasulić, J. Knežević-Vukčević "Improvement of common bean growth by co-inoculation with Rhizobium and plant growthpromoting bacteria" 2011.

[27] D.P. Oliveira, B.L. Soares, F.A.D. Martins, L.A. Franceschini, B.E. da S. Cardillo, M. Rufini, A.R. de Morais, F.M. de S. Moreira, M.J.B. de Andrade "Viability of liquid mediuminoculation of Rhizobium etli in planting furrows with common bean" Pesqui. Agropecu. Bras. 53: (2018). https://doi.org/10.1590/S0100-204X2018000300015.

[28] T. Ribeiro, D.A. Da Silva, J.A. de F. Esteves, C.V.G. Azevedo, J.G.R. Gonçalves, S.A.M. Carbonell, A.F. Chiorato "Evaluation of common bean genotypes for drought tolerance" Bragantia. 78: (2019). https://doi.org/10.1590/1678-4499.2018002.

[29] S.K. Pandey, H. Singh, A Simple " Cost-Effective Method for Leaf Area Estimation" J. Bot. 2011 :(2011) 1-6. https://doi.org/10.1155/2011/658240. 
[30] V. Fogliano, A. Ballio, M. Gallo, S. Woo, F. Scala, M. Lorito "Pseudomonas Lipodepsipeptides and Fungal Cell Wall-Degrading Enzymes Act Synergistically" Biological Control, 2002.

[31] G. Forchetti, O. Masciarelli, S. Alemano, D. Alvarez, G. Abdala "Endophytic bacteria in sunflower (Helianthus annuus L.): Isolation, characterization, and production of jasmonates and abscisic acid in culture medium" Appl. Microbiol. Biotechnol. 76: (2007) https://doi.org/10.1007/s00253-007-1077-7.

[32] C. Felici, L. Vettori, E. Giraldi, L.M.C. Forino, A. Toffanin, A.M. Tagliasacchi, M. Nuti "Single and co-inoculation of Bacillus subtilis and Azospirillum brasilense on Lycopersicon esculentum: Effects on plant growth and rhizosphere microbial community" Appl. Soil Ecol. 40: (2008). https://doi.org/10.1016/j.apsoil.2008.05.002.

[33] M.R. Swain, R.C. Ray " Biocontrol and other beneficial activities of Bacillus subtilis isolated from cowdung microflora" Microbiol. Res. 164:

(2009) https://doi.org/10.1016/j.micres.2006.10.009.

[34] O.A. Martínez, M.A. Jorquera, D.E. Crowley, M.L. de la Mora "Influence of nitrogen fertilisation on pasture culturable rhizobacteria occurrence and the role of environmental factors on their potential PGPR activities" Biol. Fertil. Soils. 47: (2011). https://doi.org/10.1007/s00374-011-0593-X.

[35] V. Nehra, Plant Growth Promoting Rhizobacteria : A Critical Review BS Saharan, (2011).

[36] A. Goryluk-Salmonowicz, A. Orzeszko-Rywka, M. Piórek, H. Rekosz-Burlaga, A. Otłowska, D. Gozdowski, M. Błaszczyk "Plant growth promoting bacterial endophytes isolated from Polish herbal plants" Acta Sci. Pol. Hortorum Cultus. 17: (2018). https://doi.org/10.24326/asphc.2018.5.9.

[37] A.N. Yadav " Plant Microbiomes and Its Beneficial Multifunctional Plant Growth Promoting Attributes" Int. J. Environ. Sci. Nat. Resour. 3: (2017). https://doi.org/10.19080/ijesnr.2017.03.555601.

[38] S. Dharni, A.K. Srivastava, A. Samad, D.D. Patra " Impact of plant growth promoting Pseudomonas monteilii PsF84 and Pseudomonas plecoglossicida PsF610 on metal uptake and production of secondary metabolite (monoterpenes) by rose-scented geranium 
(Pelargonium graveolenscv. bourbon) grown on tannery sludge amended soil", Chemosphere. 117: (2014). https://doi.org/10.1016/j.chemosphere.2014.08.001.

[39] J.P. Verma, J. Yadav, K.N. Tiwari " Enhancement of Nodulation and Yield of Chickpea by Co-inoculation of Indigenous Mesorhizobium spp. and Plant Growth-Promoting Rhizobacteria in Eastern Uttar Pradesh" Commun. Soil Sci. Plant Anal. 43: (2012). https://doi.org/10.1080/00103624.2012.639110.

[40] O. Masciarelli, A. Llanes, V. Luna " A new PGPR co-inoculated with Bradyrhizobium japonicum enhances soybean nodulation" Microbiol. Res. 169: (2014). https://doi.org/10.1016/j.micres.2013.10.001.

[41] W.D. Teale, I.A. Paponov, F. Ditengou, K. Palme " Auxin and the developing root of Arabidopsis thaliana" Physiol. Plant. 123: (2005). https://doi.org/10.1111/j.13993054.2005.00475.x.

[42] B. Borah, R. Ahmed, M. Hussain, P. Phukon, S.B. Wann, D.K. Sarmah, B.S. Bhau "Suppression of root-knot disease in Pogostemon cablin caused by Meloidogyne incognita in a rhizobacteria mediated activation of phenylpropanoid pathway" Biol. Control. 119: (2018). https://doi.or g/10.1016/j.biocontrol.2018.01.003. 
تحسين نمو نبات الفاصوليا Phaseolus vulgaris عن طريق التلقيح بالبكتيريا الجذرية المحلية متعددة الوظائف و المعزولة من التربة الملاصقة للجذور في قطاع غزة فلـ فلسطين

نضال سليم أبوحجير1، شيماء محمد عبد السلام2*، فضل أكرم الثريف3، منى اسحق فهل²

1: - قسم العلوم الطبية_ كلية العلوم و التكنولوجيا- قطاع غزة - فلسطين.

2: قسم النباتـ كلية البنات للآداب و العلوم و التربيةـ جامعة عين شمس- القاهرة- مصر.

3: قسم التكنولوجيا الطبية ـ كلية العلوم الصحية ـ الجامعة الإسلامية ـ قطاع غزةـ فلسطين.

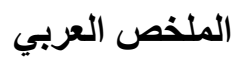

يعتبر الإفراط في استخدام الأسمدة الكيميائية مشكلة عالمية كان لها تأثير سلبي على تكوين التربة ومجتمعاتها الميكروبية. أجريت الدراسة الحالية لعزل وتحديد البكتبريا الجذرية الدحفزة لنمو النبات (PGPR) المرتبطة بنبات الفاصولياء (Phaseolus vulgaris)

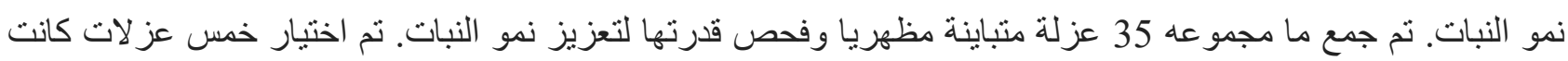

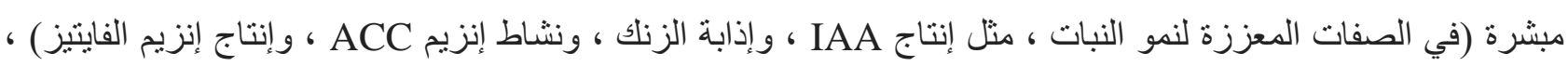
وتم إخضاعها لفحص التسلسل الجيني Bacillus proteinolyticus و Pseudomonas plecoglossicida MK123400 و Bacillus wiedmannii MK123399 MK123398 Pseudomonas cedrina MK123401 و و Bacillus xiamenensis MK123402 و أثارت النتائج إلى أن بعض النوليفات البكتيرية أدت إلى زيادة معنوية في نمو النبات ، ولكن لم تلاحظ زيادة معنوية في تركيز النيتروجين الكلي. كما أظهرت النتائج أن اجراء معاملات باستخدام (P. plecoglossicida + P. ، B. protolyticus + B. xiamenensis) $($ B. protolyticus $+P . \quad$ (B. proteinolyticus $+B$. wiedmannii + B. xiamenensis $)$ ،cedrina $)$ أدت (B. wiedmannii + P. plecoglossicida) و (B. wiedmannii plecoglossicida + B. xiamenensis)

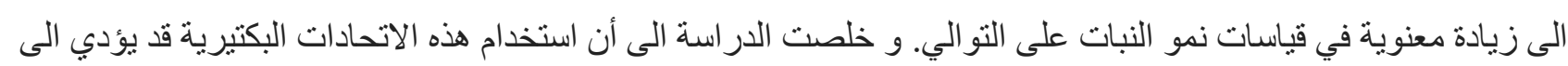

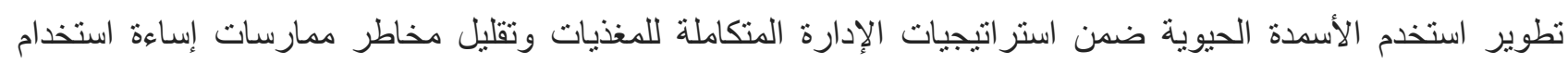

